\title{
STRIVING FOR TEACHING EXCELLENCE IN REMOTE COURSE DELIVERY: AN INTRANET RESOURCE HUB FOR ENGINEERING FACULTY
}

\author{
Anita M. Parker, Nicole Dyck, Jason P. Carey \\ Faculty of Engineering, University of Alberta, Edmonton, Alberta \\ aparker@ualberta.ca,jpcarey@ualberta.ca
}

\begin{abstract}
Teaching online in higher education is a complex integration of educational technologies, good pedagogical practices, and content knowledge. Concerns and resistance by instructors may be fueled by lack of understanding and resources, to which faculty administration can respond with targeted, ongoing communication and education. A faculty intranet initiative within the Faculty of Engineering at the University of Alberta was created to support instructors amidst their efforts to prepare and deliver online, remote versions of their courses for the Fall 2020 term. The intranet infrastructure was well-suited for the relevant, timely, and tailored digital resources specific to engineering content and circumstances. Beyond the COVID-19 pandemic, it is intended for the intranet to grow into a collaborative virtual space where users can share their knowledge, experience, and insights to build a community of practice.
\end{abstract}

Keywords: Engineering education, online learning, TPACK model, faculty intranet, knowledge sharing, faculty support

\section{INTRODUCTION}

Instructors in higher education require support from faculty administration for the design and delivery of courses in an online, remote delivery context. $[4,5]$ Teaching online is a complex integration of the effective use of educational technologies, good pedagogical practices, and content knowledge.[8, 14] Transitioning away from an in-person classroom requires the adjustment and generation of course materials, rethinking of teaching methods, and transformation of the role of the instructor to now guide student learning from a distance. [9]

In mid-March of 2020, instructors in the Faculty of Engineering at the University of Alberta suddenly found themselves teaching and working from home as part of an institution-wide emergency response to the COVID-19 pandemic. In-person classes were cancelled, and instructors led their students through the remainder of the Winter term online. In the following months, all instructors were required to prepare their courses for a wholly online, remote delivery format in time for the Fall 2020 term. It was expected that these courses would be of higher quality and sustainability than what unfolded in the final weeks of the earlier spring term.

Teaching online extends beyond replacing the bricks and mortar of an in-person classroom with web conferencing. The complexity of teaching online can be visualized with the TPACK (technological, pedagogical, content knowledge) framework, as shown in Figure 1. TPACK is a Venn diagram with three circles, one for each area of knowledge and expertise required by a digital-age instructor.[14] The intersection where all three circles overlap represents the required ability to integrate beneficial educational technologies with meaningful learning experiences to scaffold student mastery of discipline-specific content.[14]

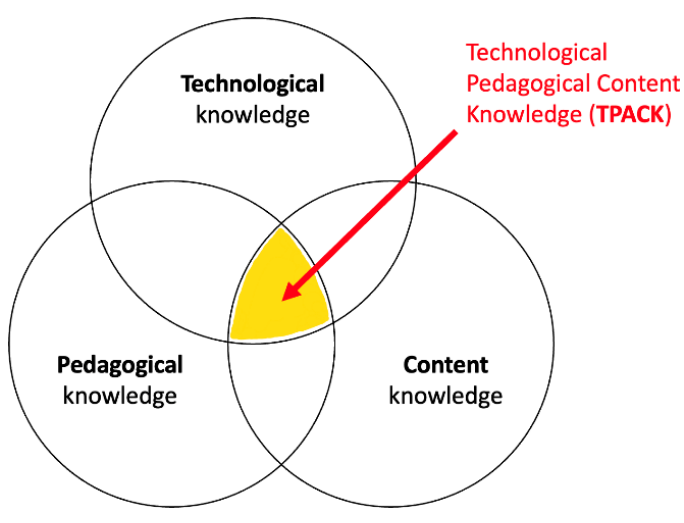

Fig. 1. Technological pedagogical content knowledge framework (TPACK) (adapted from Mishra \& Koehler, 2006).

An intranet (an internal website with access limited to intended users) is one means for faculty administration to provide current and timely support for instructors. With TPACK in mind, the Online Teaching Resource Hub for Engineering Faculty intranet was built over the summer months of 2020. The resource hub is under construction 
indefinitely due to ever-changing technologies and teaching circumstances, which is well accommodated by the editable nature of the intranet infrastructure.

The purpose of this paper is to showcase the current organization and artifacts of the resource hub, the development of which continues to be guided by the question, "What kinds of communication and education do faculty require as they redesign their courses for wholly online, remote delivery?" It is intended that by sharing the details of this initiative, it can be considered, replicated, or adapted by similar faculties elsewhere.

\subsection{Review of the Literature}

The intersection point of the technological, pedagogical, and content knowledge realms of the TPACK framework depicts the challenging nature of teaching online. $[8,14]$ Instructors in higher education are experts in their disciplines; however, many likely did not enter their classrooms with proficiency in using educational technology to craft and implement active learning experiences for students. Instead, this is a skill that would be acquired over time through years of cyclic practice and reflection.[4]

Resistance by instructors to teaching online results from an entanglement of concerns, such as the additional workload and time required to prepare and teach, and the level of competency with digital tools required by both instructors and students.[3,9,15] It is estimated that preparatory, teaching, and technical tasks of online courses require an investment of 20 percent more time by an instructor, as compared to in-person courses.[15] Also, some instructors question the legitimacy and value of online learning overall. $[3,9]$ While resistance is a natural sense-making process, in this case it may be fueled by a lack of understanding and resources, which in turn can be addressed through targeted, ongoing communication and education from faculty administration. [2, 7, 10]

An intranet is a password-protected virtual environment that, when used in a higher education context, provides instructors with information and tools, and can also function as a space for knowledge sharing and collaboration.[7] Intranets are relatively new to higher education; they have roots in the corporate realm since the mid-1990s and have been evolving in shape and purpose alongside web-based technologies.[6, 7, 12] A faculty intranet can capture, organize, and disseminate information in a timely and efficient manner. $[6,7,12,13]$ The dynamic nature of such a platform allows its content to remain current and relevant. Intranets are a means to communicate streamline and clear messages, avoid redundancies and misconceptions, and provide valuable assistance the moment it is needed. Content can be tailored for instructors who are trailblazers ready for the next challenge, or for those who are overwhelmed and not sure where to begin. A faculty intranet can be two-way, inviting knowledge sharing and collaboration by its users and thus serve in the building of a community of practice. $[6,7,12]$

The effectiveness and impact of an intranet, and alternately its susceptibility to inertia, are connected to organizational, technological, and individual factors. Successful intranets require vision and commitment by leadership, a robust infrastructure and intelligent design, and basic technological competence and a perception of usefulness by the user.[6]

\section{METHODOLOGY}

The Online Teaching Resource Hub for Engineering Faculty is an internal faculty website (intranet) that was, and continues to be, built with the TPACK framework in mind (specifically its Venn diagram intersection point, Figure 1). The resource hub is not a haphazard repository of how-to's for digital tools, but rather a thoughtful organization and presentation of engineering-specific examples of technology-enhanced pedagogy.

A parallel institution-wide resource website was deemed to be overly broad and arduous, and in-house piecemeal tips and tricks being shared among colleagues lacked cohesiveness. Therefore, hub developers strived to find a balanced "Goldilocks zone" of digital resources to specifically benefit engineering instructors who were working in geographically dispersed circumstances and preparing to teach their courses entirely online in the Fall 2020 term.

The robustness and familiarity of eClass, the University's learning management system (Moodle), made it a decidedly appropriate infrastructure for the hub's content, available 24/7. Presently, the hub brings together external links to text and video content focused on faculty policies and guidelines, the technology and pedagogy of online courses (developing, delivering, and assessment of student learning), online labs and open educational resources (OER), how graduate attributes factor into online teaching, and academic literature that supports decisions and actions. Content is organized into sections using headings deemed most succinct and clear to indicate the nature of the communication and education provided, as shown in Table 1.

\section{FINDINGS}

As a result of fluctuating circumstances and tight deadlines, direct evidence (site analytics) or indirect evidence (user surveys) has not yet been collected to measure the effectiveness of the Online Teaching Resource $\mathrm{Hub}$ for Engineering Faculty intranet for the benefit of informing its further development. Garnering empirical evidence is planned once the teaching and learning situation normalizes. Currently, findings are limited to lessons learned about the layout and content of the site as hub developers remained focused on the guiding question, 
"What kinds of communication and education do faculty require as they redesign their courses for wholly online, remote delivery?" The response to this question is manifested in the words carefully chosen for the section headings, as shown in Table 1.

Table 1: Section headings of the resource hub as they relate to communication and education provided by faculty administration.

\begin{tabular}{|l|c|}
\hline \multicolumn{1}{|c|}{ Section Heading } & $\begin{array}{c}\text { Communication } \\
\text { and/or Education? }\end{array}$ \\
\hline $\begin{array}{l}\text { Policy \& Guidelines for Engineering } \\
\text { Faculty }\end{array}$ & communication \\
\hline How to Build Your Online Course & education \\
\hline How to Teach Your Online Course & education \\
\hline $\begin{array}{l}\text { Assessment of Student Learning in Your } \\
\text { Online Course }\end{array}$ & $\begin{array}{c}\text { communication, } \\
\text { education }\end{array}$ \\
\hline $\begin{array}{l}\text { Content Resources for Your Online } \\
\text { Course (OER, virtual labs) }\end{array}$ & \begin{tabular}{c} 
education \\
\hline $\begin{array}{l}\text { Academic Literature on Online Teaching } \\
\text { in Engineering }\end{array}$
\end{tabular} \\
\hline
\end{tabular}

Site Layout: Lessons learned about site layout were related to maximizing the user experience, namely ease of navigation and location of materials quickly and effortlessly. This was found to be enhanced by:

- A collapsible topics framework with logical headings and subheadings

- Well-labeled links with intuitive, consistent terminology

- Minimal number of clicks to reach destination

- Colour and highlighting strategies for readability

Site Content: Lessons learned about the site content were aggregated to provide a focused, uncluttered user experience, i.e. trimming the unwieldiness of what is available online into an engineering context

- Keep TPACK in mind to include the pedagogical application and value of digital tools

- Ensure that all content is as specific to engineering education as possible

- Less is more; the "Cliff notes" version best accommodates user needs and time constraints

- Update regularly, replacing dead links and ensure all artifacts remain current and relevant

\section{DISCUSSION}

Support provided by faculty administration can impact the motivation, commitment, and confidence of instructors as they develop and teach online courses. This has a ripple effect on the learning experience and success of students.[5] The TPACK framework, in particular the intersection of its technological and pedagogical components, pinpoints the complexity of teaching online and how a lack of understanding and resources can result in instructor resistance.[14] This can inform the type of communication and education provided by faculty administration that is necessary and valuable to instructors.[2]

When instructors in the Faculty of Engineering at the University of Alberta responded to an unanticipated and all-encompassing shift from in-person to remote course delivery in March 2020, they focused on temporary fixes to complete the Winter term. Their work continued through the spring and summer months to create more sustainable, quality versions of their online courses. With this in mind, the Online Teaching Resource Hub for Engineering Faculty intranet initiative was fast-tracked so it could be of assistance at this critical time. Historically and universally, undergraduate engineering education has notably lagged behind other disciplines in the development and delivery of online learning, presumably due to its strong laboratory component.[1] Therefore, redesigning courses within an unforgiving deadline was a formidable challenge, for which engineering instructors at the University of Alberta required immediate support. A brief summary of the content organized into each section of the hub is as follows.

The Policy \& Guidelines for Engineering Faculty section provides top-down documentation about best practices and expectations for remote teaching. Details cover the delivery of lectures, seminars, labs, office hours, assessments, and more, all for the purpose of achieving faculty-wide cohesiveness. For example, instructors are asked to blend asynchronous and synchronous modalities, be accommodating for students in different time zones, provide non-print resources such as e-books, and avoid eproctoring when possible. As is customary, instructors are afforded flexibility and discretion within the specifications.

The How to Build Your Online Course section provides just-in-time assistance for instructors as they redesign their courses for remote delivery. This includes a self-study course about teaching and learning online, a knowledgebase of how-to articles for building their course sites in eClass, and tutorials covering the creation of asynchronous content, such as the narration of a slide presentation or pre-recording a lecture in Zoom.

The How to Teach Your Online Course section brings together a host of strategies and ideas for instructors to facilitate a student-centered experience under geographically distanced circumstances. Here, content is focused on transitioning the usual, in-person student engagement activities for comparable implementation in the virtual classroom. For example, instructors can access an online instructional index of more than 40 activity ideas, guidelines for productive and respectful forum participation, and creating student study groups using Google Meet video conferencing. 
The Assessment of Student Learning in Your Online Course section addresses the pedagogical and technological components of online assessments. Instructors are encouraged to rethink high-stakes, closedbook exams and opt for assessments that are better suited to a virtual environment. Here, instructors can also learn about eClass settings and strategies for upholding academic integrity by students, and how to author a bank of numerical questions that are characteristic of engineering courses.

The Content Resources for Your Online Course section is a portal to virtual labs, activities, and open-educational resources that are specific to experiential nature of engineering learning outcomes. External links take instructors to ideas for in-house development and thirdparty lab content (free and for-cost), such as simulations and videos. Pedagogical guidance is also provided, such as points to consider if choosing to create lab kits for students to unpack and use at home.

Finally, the Academic Literature for Online Teaching in Engineering section is included for instructors who are interested in further reading on the topic. An annotated bibliography allows the reader to quickly assess the relevance of each source, and links to full digital copies are provided. Sources are primary (a single empirical study) or secondary (a review, essay, or book chapter) and published in a reputable scholarly journal, conference proceeding, or book.

It was important that the hub's content be as connected to engineering education as possible in hopes of making it unnecessary for instructors to conduct endless internet searches for answers to their questions-likely the same questions being asked by their colleagues, unknowingly because of geographically distanced workspaces. One submission to the hub by a University of Alberta engineering instructor was a detailed account of how academic integrity was maintained in an open-book environment by the use of transparent communication with students and creative use of eClass settings. This step-bystep document with text and images undoubtedly helped other instructors facing this same challenge. Another example of engineering-specific content is a tipsheet series (printable PDFs) aligning graduate attributes (as required for accreditation) with digital tools (collaborative spaces such as wikis and social annotation, as well as eportfolios) with strategies for creating active, authentic experiences for students learning remotely. This tipsheet series is another manifestation of the TPACK intersection point. Hub development continued into the Fall 2020 term, with tweaking and enriching of its content as instructors were in the throes of course delivery with students. For instance, instructors initially needed to know the basics of Zoom web conferencing (i.e., what to click on the screen); after mastering this, they were more interested in its pedagogical potential.
The eClass platform is well-suited for the creation of an intranet, in this case the resource hub that is presently a one-way flow of communication and education from faculty administration to instructors, providing clear messaging and relevant and timely assistance. The versatility of the platform can also accommodate the hub's envisioned future growth to being a more collaborative space, where it would welcome the sharing of tangible lessons, knowledge, experiences, and insights, of its users. Because knowledge is a social construct, collaboration via the resource hub would heighten the skill level of all users, in terms of the design and delivery of online courses.

\section{CONCLUSION}

Instructors teaching in an online environment in higher education are tasked with integrating educational technologies, good pedagogical practices, and content knowledge, for which they require support from faculty administration. A faculty intranet initiative within the Faculty of Engineering at the University of Alberta was, and continues to be, a vehicle to bring education and communication to instructors amidst their pandemicdriven efforts to prepare and deliver online, remote versions of their courses in the Fall 2020 term. The intranet infrastructure is well-suited for the relevant, timely, and tailored digital resources specific to engineering content and circumstances. Intranet sections were carefully organized to: communicate faculty-specific policies and guidelines; provide just-in-time assistance for building competence with digital tools; suggest ideas and strategies for active, authentic learning activities; encourage rethinking of traditional assessments; and link to external materials, such as virtual labs and open educational resources.

Due to the ongoing nature of the pandemic, findings from this initiative are limited to lessons learned about site construction, namely content selection and layout. It is intended for the intranet to grow into a collaborative space where users can share their knowledge, experience, and insights to build a community of practice.

\section{Acknowledgements}

The authors wish to acknowledge the Faculty of Engineering at the University of Alberta for supporting the Online Teaching Resource Hub for Engineering Faculty intranet initiative.

\section{References}

[1] S. Badjou and R. Dahmani, "Current status of online science and engineering education," Journal of Online Engineering Education, vol. 4, no. 1, p. 9pp., 2013.

[2] M. Bresciani, Outcomes-based academic and cocurricular program review: a compilation of 
institutional good practices, Sterling, VA: Stylus, 2006.

[3] B. D. Espinoza and M. Neal, "Incorporating contextual knowledge in faculty professional development for online teaching," Journal on Centers for Teaching and Learning, vol. 10, pp. 24-44, 2018.

[4] D. A. Frayer, "Creating a campus culture to support a teaching and learning revolution," Cause/Effect, vol. 22, no. 2, 1999.

[5] S. Guan and D. Stanford, "Learner and faculty support," New Directions for Higher Education, vol. 2016, no. 173, pp. 65-74, 2016.

[6] K. Herson, M. Sosabowski, A. Lloyd, S. Flowers, C. Paine and B. Newton, "Implementation strategies for educational intranet resources," British Journal of Educational Technology, vol. 31, no. 1, pp. 47-55, 2000.

[7] S. Hickling, A. Bhatti, G. Arena, J. Kite, N. L. I. Spencer and D. C. Bowles, "Adapting to teaching during a pandemic: Pedagogical adjustments for the next semester of teaching during COVID-19 and future online learning," Pedagogy in Health Promotion, p. 8pp., 2021

[8] S. Jaikaran-Doe and P. E. Doe, "Assessing technological pedagogical content knowledge of engineering academics in an Australian regional university," Australasian Journal of Engineering Education, vol. 20, no. 2, pp. 157-167, 2015.

[9] M. Kebritchi, A. Lipschuetz and L. Santiague, "Issues and challenges for teaching successful online courses in higher education: A literature review," Journal of Educational Technology Systems, vol. 46, no. 1, pp. 429, 2017.

[10] L. Li, C. Lin and G. Lai, "Technology sensemaking by university administrators, faculty and staff: Unity and divergence," International Journal of Technology in Teaching and Learning, vol. 12, no. 1, pp. 1-16, 2016.

[11] M. F. Lo and F. Tien, "How academic leaders facilitate knowledge sharing: A case of universities in Hong Kong," Leadership \& Organization Development Journal, vol. 41, no. 6, pp. 777-798, 2020.

[12] A. Martini, M. Corso and L. Pellegrini, "An empirical roadmap for intranet evolution," International Journal for Information Management, vol. 29, pp. 295-308, 2009.

[13] M. N. Masrek, N. S. A. Karim and R. Hussein, "Investigating corporate intranet effectiveness: A conceptual framework," Information Management \& Computer Security, vol. 15, no. 3, pp. 168-183, 2007.

[14]P. Mishra and M. J. Koehler, "Technological pedagogical content knowledge: A framework for teacher knowledge," Teachers College Record, vol. 108, no. 6, pp. 1017-1054, 2006.

[15] W. L. Worley and L. S. Tesdell, "Instructor time and effort in online and face-to-face teaching: Lessons learned," IEEE Transactions on Professional Communication, vol. 52, no. 2, pp. 138-151, 2009. 